\title{
PRODUÇÃO DE MUDAS DE VIDEIRA 'ITÁLIA' ATRAVÉS DE ENXERTIA VERDE EM PORTA-ENXERTOS PROPAGADOS POR ESTACAS HERBÁCEAS ${ }^{1}$
}

\author{
SÉRGIO RUFFO ROBERTO², CARMEN SILVIA VIEIRA JANEIRO NEVES ${ }^{3}$, BRUNO DA SILVA JUBILEU ${ }^{4}$, MATEUS \\ CARVALHO BASÍLIO DE AZEVEDO
}

\begin{abstract}
RESUMO - O presente trabalho teve por objetivo estudar a viabilidade da produção de mudas de videira 'Itália' (Vitis vinifera L.) através de enxertia verde nos porta-enxertos IAC 766 'Campinas' e IAC 572 'Jales' propagados por estaquia herbácea. O preparo das estacas, a partir de porta-enxertos livres de vírus, consistiu em deixar apenas uma folha na parte superior da estaca e um nó na base, ficando as mesmas com $20 \mathrm{~cm}$ de comprimento e 0,5 $\mathrm{cm}$ de diâmetro. As estacas foram então dispostas para enraizamento em caixas plásticas perfuradas contendo o substrato casca de arroz carbonizada em câmara de nebulização. Verificado o enraizamento, os porta-enxertos foram transplantados para sacos de polietileno com substrato à base de terra e mantidos em casa de vegetação. Avaliou-se a enxertia da videira 'Itália' realizada aos 30; 60 e 90 dias após o transplante dos porta-enxertos. O delineamento estatístico foi o inteiramente casualizado, com 6 tratamentos e 5 repetições, sendo cada parcela composta por 10 mudas, em esquema fatorial 2 × 3 . O efeito de cada fator, porta-enxertos e épocas de enxertia verde após o transplante, na produção das mudas, foi avaliado aos 80 dias após cada época de enxertia, através das seguintes variáveis: porcentagem de enxertos brotados; comprimento e diâmetro dos brotos; pesos da matéria seca e fresca das raízes por muda; e área de raízes e comprimento total de raízes por estaca, através da análise de imagem no programa SIARCS®. Com base nos principais resultados, pode-se concluir que é possível a obtenção de mudas de videira 'Itália', realizando-se a enxertia verde em portaenxertos herbáceos após 90 dias do seu enraizamento, com 77,50\% de pegamento médio dos enxertos.
\end{abstract}

Termos para indexação: Vitis spp., propagação, estaquia.

\section{PRODUCTION OF 'ITALIA' GRAPEVINE NURSERY PLANTS THROUGH GREEN GRAFTING IN HERBACEOUS ROOTSTOCKS}

\begin{abstract}
The objetive of this research was to evaluate the feasibility to produce nursery plants of 'Italia' grapevine through green grafting on herbaceous cutting of two rootstocks (IAC 766 'Campinas' and IAC 572 'Jales'). Rootstocks cuttings were taken from a virus-free stock plant, and consisted of the leaves elimination of the basal portion, leaving just one leaf in the superior part of each one. Cuttings were prepared with a cut below the node in the basal portion and a cut in the internode in the superior portion, leaving each one with $20 \mathrm{~cm}$ of length and $0.5 \mathrm{~cm}$ of diameter. Cuttings were then placed in plastic boxes containing coaled hull rice medium on mist chamber. Once the properly rooting was observed, the rootstocks were transferred into plastic bags containing soil mix. The 'Italia' green grafting was evaluated in three different periods after the rootstocks transplantation (30, 60 and 90 days). A randomized design was used as statistical model with 6 treatments and 5 replications in a 2-factor arrangement (2 rootstocks and 3 periods of grafting). Each plot was composed by 10 plants. The treatments were compared 80 days after each grafting period through the following parameters: porcentage of shooting grafts, length and diameter of shooting grafts, fresh and dry weigth of roots, and root quantification (root area and total root length) through image analysis using SIARCS® software. It was possible to conclude that the production of nursery plants of 'Italia' grapevine can be reached, performing the green grafting, 90 days after the transplantation of rooted herbaceous cuttings into plastic bags, with $77.50 \%$ of well-succesfull grafting.
\end{abstract}

Index terms: Vitis spp., propagation, rooting.

\section{INTRODUÇÃO}

A produção de mudas de videira de boa qualidade e livres de vírus constitui-se fator básico para o sucesso da cultura, uma vez que a formação inicial da planta se reflete por toda sua vida produtiva (Rezende \& Pereira, 2001).

No Brasil, os vinhedos são formados, em sua maioria, através do processo de enxertia por garfagem, realizada no campo, durante o inverno. Os porta-enxertos são obtidos por estaquia lenhosa diretamente no local definitivo do vinhedo ou em recipientes, com posterior plantio em campo. Para a formação do vinhedo por este processo, são necessários cerca de dois anos, existindo ainda a possibilidade de ocorrência de falhas no pegamento das enxertias (Sousa, 1996; Terra et al., 1998; Pires \& Biasi, 2003).

Mais recententemente no Brasil, tem-se verificado também o plantio de vinhedos comerciais através da importação de mudas enxertadas obtidas pela técnica da enxertia de mesa. Os valores dessa prática não estão disponíveis, mas sabe-se que ela é crescente e está estimada em mais de 1 milhão de plantas por ano no Sul do País (Regina, 2002). Assim, a busca constante de inovações com a finalidade da obtenção de mudas de qualidade, em um menor espaço de tempo, justifica o estudo e o emprego de novas tecnologias no sistema produtivo (Rezende \& Pereira, 2001).

A enxertia verde, mundialmente conhecida e utilizada em alguns países produtores, encontra-se entre os processos de formação rápida do vinhedo, reduzindo em aproximadamente um ano a produção de mudas. A enxertia verde em porta-enxertos propagados por estaquia herbácea pode ser um processo eficiente para a formação rápida do vinhedo, resultando na produção de grande quantidade de mudas e em significativa redução no tempo para sua obtenção em qualidade, além de evitar falhas da operação de enxertia em campo, que normalmente ocorrem no processo convencional. Entretanto, poucas informações estão disponíveis em relação às características da produção de mudas de videira por este processo no Brasil, o que motivou a presente pesquisa.

\footnotetext{
${ }^{1}$ (Trabalho 090/2003). Recebido: 23/05/2003. Aceito para publicação: 07/01/2004. Parte do projeto 474709/01-9 financiado pelo CNPq na modalidade Auxílio à Pesquisa.

2 Professor Adjunto, Dr. Área de Fruticultura. Bolsista de Produtividade em Pesquisa do CNPq. Universidade Estadual de Londrina - UEL. Centro de Ciências Agrárias. Caixa Postal 6001. 86051-990. Londrina-PR. Tel: (43) 3371 4774. Autor correspondente: sroberto@uel.br.

${ }^{3}$ Professor Associado, Dr. Área de Fruticultura. Bolsista de Produtividade em Pesquisa do CNPq. Universidade Estadual de Londrina - UEL. Centro de Ciências Agrárias. Caixa Postal 6001. 86051-990. Londrina-PR. Tel: (43) 3371 4770. e-mail: csvjneve@uel.br.

${ }^{4}$ Acadêmico do Curso de Graduação em Agronomia. Universidade Estadual de Londrina - UEL. Centro de Ciências Agrárias. Caixa Postal 6001. 86051-990. LondrinaPR. e-mail: brunojubileu@yahoo.com.br.

${ }^{5}$ Aluno regulador do Curso de Mestrado em Agronomia e Bolsista da CAPES. Universidade Estadual de Londrina - UEL. Centro de Ciências Agrárias. Caixa Postal 6001.86051-990. Londrina-PR.e-mail: mcbazevedo@ hotmail.com.
} 
TABELA 1 - Análise de variância da porcentagem de enxertos brotados, e comprimento e diâmetro dos brotos da videira 'Itália' (Vitis vinifera L.) enxertada aos 30; 60 e 90 dias após o transplante dos porta-enxertos IAC 766 'Campinas' e IAC 572 'Jales' propagados por estaquia herbácea em câmara de nebulização. Londrina-PR, 2003.

\begin{tabular}{|c|c|c|c|c|}
\hline Porta-enxerto & & \% de enxertos brotados ${ }^{a}$ & comprimento dos brotos $(\mathrm{cm})^{\mathrm{a}}$ & diâmetro dos brotos $(\mathrm{mm})^{\mathrm{a}}$ \\
\hline IAC 766 'Campinas' & & $42,50 \mathrm{a}$ & $64.85 \mathrm{a}$ & $31.60 \mathrm{a}$ \\
\hline IAC 572 'Jales' & & $37,50 \mathrm{a}$ & $63,59 \mathrm{a}$ & $31,60 \mathrm{a}$ \\
\hline \multicolumn{5}{|l|}{$\begin{array}{l}\text { Época de enxertia após } \\
\text { o transplante (dias) }\end{array}$} \\
\hline 30 & & $12,50 \mathrm{c}$ & $54,44 \mathrm{~b}$ & $30,90 \mathrm{~b}$ \\
\hline 60 & & $30,00 \mathrm{~b}$ & $67,49 \mathrm{a}$ & $31,70 \mathrm{ab}$ \\
\hline 90 & & $77,50 \mathrm{a}$ & $70,73 \mathrm{a}$ & $32,20 \mathrm{a}$ \\
\hline Causas de variação & GL & & $\mathbf{F}$ & \\
\hline Porta-enxertos (PE) & 1 & $1,94 \mathrm{~ns}$ & $0,50 \mathrm{~ns}$ & $0,00 \mathrm{~ns}$ \\
\hline $\begin{array}{c}\text { Época de enxertia após } \\
\text { o transplante (EEAT) }\end{array}$ & 2 & $117,40 * *$ & $31,75 * *$ & $4,44 *$ \\
\hline Interação PE x EEAT & 2 & 0,00 & $0,98 \mathrm{~ns}$ & $0,72 \mathrm{~ns}$ \\
\hline Resíduo & 24 & - & - & - \\
\hline
\end{tabular}

Médias seguidas das mesmas letras nas colunas não diferem entre si, pelo Teste de Tukey $(P<0,05)$.

a: Avaliado aos 80 dias após a enxertia.

ns: não significativo.

**: significativo $(P<0,01)$.

Tendo em vista estes aspectos, este trabalho foi conduzido, visando-se a avaliar a viabilidade da produção comercial de mudas da videira 'Itália' (Vitis vinifera L.) através de enxertia verde em estacas herbáceas de porta-enxertos enraizadas em câmara de nebulização, variando-se a época de enxertia após o transplante dos porta-enxertos.

\section{MATERIALEMÉTODOS}

O experimento foi realizado no setor de Fruticultura do Centro de Ciências Agrárias, Departamento de Agronomia, da Universidade Estadual de Londrina - UEL, Paraná, a partir de dezembro de 2001.

Foi avaliada a produção de mudas da videira 'Itália' (Vitis vinifera $\mathrm{L}$.) empregando-se os porta-enxertos IAC 766 'Campinas' e IAC 572 'Jales'. Para tanto, estacas herbáceas dos dois porta-enxertos foram retiradas de plantas-matrizes pertencentes a uma coleção livre de vírus, a partir das porções de ramos tenros e verdes, onde se evitaram as terminais e as em início de lignificação. O preparo das estacas consistiu em um corte horizontal logo abaixo de um nó, com a eliminação das folhas da parte basal, deixando-se apenas uma folha na parte superior (Biasi et al., 1997), ficando a estaca com aproximadamente $20 \mathrm{~cm}$ de comprimento e $0,5 \mathrm{~cm}$ de diâmetro.

Após o seu preparo, as estacas dos porta-enxertos foram dispostas em caixas plásticas perfuradas, medindo $44 \times 33 \times 7 \mathrm{~cm}$, contendo o substrato casca de arroz carbonizada (CAC) e levadas em seguida para câmara de nebulização em regime intermitente até observado enraizamento adequado, o que ocorreu quatro semanas após a estaquia. O substrato CAC foi preparado no próprio setor de Fruticultura da UEL, segundo as recomendações descritas por Röber (2000).

As estacas enraizadas foram então transplantadas para sacos pretos perfurados de polietileno medindo $18 \times 30 \mathrm{~cm}$, contendo substrato constituído de mistura de terra, areia, vermiculita e esterco de curral curtido, na proporção 2:1:1:1 v/v, respectivamente.

Foram avaliadas três épocas de enxertia da videira 'Itália' após o transplante dos porta-enxertos para os sacos plásticos: 30; 60 e 90 dias. Os ramos da videira 'Itália' provenientes de matrizes livres de vírus, obtidos durante a estação de crescimento, foram enrolados em jornal umedecido, acondicionados em sacos plásticos e mantidos em câmara de nebulização até a enxertia. Todas as enxertias foram feitas por apenas um enxertador. Os garfos foram preparados com cerca de $7 \mathrm{~cm}$ de comprimento. O método de enxertia verde empregado foi o de garfagem de fenda cheia por ser o mais efetivo (Rezende \& Pereira, 2001). Após serem enxertados nos porta-enxertos, os garfos foram protegidos com fita plástica de enxertia na região dos cortes.

Adotou-se o delineamento inteiramente casualizado em esquema fatorial 2 × 3 , dois porta-enxertos e três épocas de enxertia após o transplante dos porta-enxertos, em um total de seis tratamentos, com cinco repetições, sendo cada parcela composta por 10 plantas.

$\mathrm{O}$ desenvolvimento e a formação das mudas, nas três épocas de enxertia, após o transplante dos porta-enxertos, foi avaliado aos 80 dias após cada enxertia, através das seguintes variáveis: i) porcentagem de enxertos brotados; ii) comprimento dos brotos ( $\mathrm{cm}$ ), e iii) diâmetro dos brotos (mm) (Biasi et al., 1997). Aos 80 dias após cada época de enxertia, foram avaliados também os pesos da matéria seca e fresca (g) das raízes das plantas, bem como quantificou-se o sistema radicular das mudas por imagem. As imagens foram obtidas em escâner de mesa, sendo armazenadas em formato JPEG para, posteriormente, serem quantificadas e comparadas no aplicativo SIARCS $®$, sendo analisadas as seguintes variáveis: i) área do sistema de raízes por muda $\left(\mathrm{cm}^{2}\right)$, e ii) comprimento total das raízes por muda $(\mathrm{cm})$. Os procedimentos utilizados pelo programa SIARCS® para a análise destas variáveis estão descritos em Jorge et al. (1997).

A partir destes dados, analisou-se o efeito dos fatores, portaenxertos e épocas de enxertia após o tranplante dos porta-enxertos, para cada variável na produção das mudas de videira 'Itália', através da análise de variância, e a separação das médias realizada pelo teste de Tukey, a $5 \%$ de probabilidade.

\section{RESULTADOSEDISCUSSÃO}

Para todas as variáveis analisadas na produção de mudas da videira 'Itália', a interação entre porta-enxertos e épocas de enxertia após o transplante não foi significativa, indicando que estes fatores agem de forma independente em relação a estas variáveis (Tabela 1).

A porcentagem de enxertos brotados da videira 'Itália' analisada aos 80 dias após a enxertia foi semelhante para os dois porta-enxertos, não sendo constatadas diferenças estatísticas significativas entre eles (Tabela 1). Entretanto, verificou-se que, quanto mais tardia a época de enxertia após o transplante das estacas herbáceas dos porta-enxertos enraizados em câmara de nebulização, maior foi a porcentagem de enxertos brotados. A maior porcentagem média de enxertos vivos observada foi quando se realizou a enxertia aos 90 dias após o transplante dos porta-enxertos, $77,50 \%$, diferindo significativamente das enxertias realizadas aos 30 e 60 dias após o transplante, 12,50 e 30,00\%, respectivamente.

Não foram observadas diferenças significativas entre os portaenxertos em relação ao comprimento dos brotos da videira 'Itália' (Tabela 1). Entretanto, verifica-se que as enxertias realizadas aos 60 e 90 dias após o transplante dos porta-enxertos apresentaram as maiores médias de comprimento da brotação dos enxertos nas três datas de avaliações, 
TABELA 2 - Análise de variância dos pesos da matéria fresca e seca $(\mathrm{g})$, da área $\left(\mathrm{cm}^{2}\right)$ e do comprimento total de raízes por muda (cm) da videira 'Itália' (Vitis vinifera L.) enxertada aos 30; 60 e 90 dias após o transplante dos porta-enxertos IAC 766 ‘Campinas’ e IAC 572 ‘Jales' propagados por estaquia herbácea em câmara de nebulização. Londrina-PR, 2003.

\begin{tabular}{|c|c|c|c|c|c|}
\hline Porta-enxertos & & $\begin{array}{l}\text { peso da matéria fresca das } \\
\text { raízes por muda }(\mathrm{g})^{\mathrm{a}}\end{array}$ & $\begin{array}{l}\text { peso da matéria seca das } \\
\text { raízes por muda }(\mathrm{g})^{\mathrm{a}}\end{array}$ & $\begin{array}{l}\text { área de raízes por } \\
\text { muda }\left(\mathrm{cm}^{2}\right)^{\mathrm{a} ; \mathrm{b}}\end{array}$ & $\begin{array}{l}\text { comprimento total de } \\
\text { raízes por } \\
\text { muda }(\mathbf{c m})^{\text {a;b }}\end{array}$ \\
\hline IAC 766 'Campinas' & & $34,95 \mathrm{a}$ & $6,89 \mathrm{a}$ & $123,25 \mathrm{a}$ & $263,58 \mathrm{a}$ \\
\hline IAC 572 'Jales' & & $34,32 \mathrm{a}$ & $6,73 \mathrm{a}$ & $116,01 \mathrm{a}$ & $257,96 \mathrm{a}$ \\
\hline \multicolumn{6}{|l|}{$\begin{array}{c}\text { Época de enxertia após } \\
\text { o transplante (dias) }\end{array}$} \\
\hline 30 & & $30,26 \mathrm{c}$ & $6,06 \mathrm{~b}$ & $102,93 \mathrm{c}$ & $218,37 \mathrm{~b}$ \\
\hline 60 & & $34,68 \mathrm{~b}$ & $6,69 \mathrm{ab}$ & $120,42 \mathrm{~b}$ & $275,90 \mathrm{a}$ \\
\hline 90 & & $38,95 \mathrm{a}$ & $7,69 \mathrm{a}$ & $135,55 \mathrm{a}$ & $288,08 \mathrm{a}$ \\
\hline Causas de variação & $\mathbf{G L}^{\mathbf{a}}$ & \multicolumn{4}{|c|}{$\mathbf{F}$} \\
\hline Porta-enxertos (PE) & 1 & $0,36 \mathrm{~ns}$ & $0,19 \mathrm{~ns}$ & $3,08 \mathrm{~ns}$ & $1,66 \mathrm{~ns}$ \\
\hline $\begin{array}{l}\text { Época de enxertia após } \\
\text { o transplante (EEAT) }\end{array}$ & 2 & $22,83 * *$ & $7,44 * *$ & $20,91 * *$ & $98,84 * *$ \\
\hline Interação PE x EEAT & 2 & $0,15 \mathrm{~ns}$ & $0,01 \mathrm{~ns}$ & $0,66 \mathrm{~ns}$ & $4,42 \mathrm{~ns}$ \\
\hline Resíduo & 24 & - & - & - & - \\
\hline
\end{tabular}

Médias seguidas das mesmas letras nas colunas não diferem entre si, pelo Teste de Tukey $(P<0,05)$.

a: Avaliado aos 80 dias após a enxertia.

b: Parâmetro obtido através de análise de imagem no programa SIARCS®.

**: significativo $(P<0,01)$

ns: não significativo.

diferindo significativamente da época de realização da enxertia aos 30 dias.

Observações semelhantes foram obtidas quando avaliado o diâmetro dos brotos, para o qual os porta-enxertos apresentaram comportamento semelhante (Tabela 1). Para esta variável, nas três avaliações realizadas, as maiores médias foram obtidas quando se realizou a enxertia aos 90 dias após o transplante dos porta-enxertos, não diferindo, entretanto, da enxertia realizada aos 60 dias, que, por sua vez, não diferiu da época de enxertia realizada aos 30 dias após o transplante.

Esta influência exercida pelas épocas de enxertia mais tardia após o transplante dos porta-enxertos sobre o comprimento e o diâmetro dos enxertos da videira 'Itália' deve estar relacionada com o maior pegamento dos enxertos que estes tratamentos proporcionaram, conferindo, assim, melhores condições de desenvolvimento vegetativo para a brotação das gemas dos enxertos.

Em relação aos pesos da matéria fresca e seca das raízes das mudas, não foram observadas diferenças entre os porta-enxertos (Tabela 2). Entretanto, verificou-se que, quanto mais tardia a época de enxertia após o transplante, maior foi a média do peso da matéria fresca das raízes por muda, sendo que a maior média foi obtida quando esta foi realizada aos 90 dias após o transplante $(38,95 \mathrm{~g})$, diferindo significativamente dos demais tratamentos. Resultados semelhantes foram obtidos quanto ao peso da matéria seca das raízes por muda, onde as maiores médias foram observadas quando as enxertias foram realizadas aos 90 e 60 dias após o transplante, 7,69 e 6,69 g, respectivamente, sendo que este último tratamento não diferiu significativamente da época mais precoce, $6,06 \mathrm{~g}$. Este menor peso do sistema radicular das mudas, observado no tratamento com a realização da enxertia aos 30 dias após o transplante, deve-se ao menor período de tempo em que estas plantas permaneceram na casa de vegetação, o que não propiciou um desenvolvimento do sistema radicular mais adequado dos porta-enxertos para o pegamento e desenvolvimento dos enxertos.

Rezende \& Pereira (2001) constataram um baixo índice de sobrevivência de enxertos da videira 'Rubi' sobre o porta-enxerto IAC 313 'Tropical' realizado 15 dias após o transplante das estacas herbáceas enraizadas para sacos plásticos. Esta observação deve-se, provavelmente, ao curto período de tempo entre o transplante e a enxertia, o que acarreta em um sistema radicular menos desenvolvido dos porta-enxertos.

Diante destes resultados, presume-se que, para a produção de mudas de videira 'Itália' enxertadas sobre porta-enxertos propagados por estaquia herbácea, é fundamental um sistema radicular bem desenvolvido dos porta-enxertos para obter-se um alto índice de pegamento dos enxertos, sendo necessário, com base nos resultados obtidos neste trabalho, que os porta-enxertos enraizados sejam mantidos por, pelo menos, 90 dias em recipientes com substrato antes da realização das enxertias verdes. Diversos fatores, associados ou não, podem ter sido a causa da maior eficiência do pegamento dos enxertos quando a enxertia foi realizada mais tardiamente. Dentre eles, estão o período mais prolongado de aclimatação e o maior desenvolvimento das raízes nas condições de viveiro, os quais resultaram em maior vigor e, possivelmente, em maior acúmulo de reservas das mudas. Estes fatores, segundo Hartmann \& Kester (1990), são essenciais para maior divisão celular e união dos tecidos cambiais envolvidos, produzindo novos tecidos vasculares que permitem o fluxo normal de água e nutrientes, estabelecendo, assim, a perfeita união entre o enxerto e o porta-enxerto.

Resultados semelhantes, porém com pessegueiros, foram relatados por Nachtigal (1999). Objetivando reduzir o tempo de produção de mudas de pessegueiro, este autor concluiu que os melhores índices de pegamento dos enxertos do pessegueiro 'Biuti' enxertado em estacas herbáceas do porta-enxerto 'Okinawa' ocorreram quando a enxertia foi realizada aos 90 dias após o transplante de estacas enraizadas do portaenxerto.

Não foram observadas diferenças entre os porta-enxertos avaliados em relação à área e ao comprimento total de raízes por muda através da análise digital no programa SIARCS®, indicando que os dois porta-enxertos propagados nestas condições apresentam comportamento semelhante em relação ao seu sistema radicular (Tabela 2). Porém, foram constatadas diferenças significativas entre as três épocas de enxertia onde, em relação à área de raízes por muda, a maior média foi obtida pelo tratamento com a enxertia aos 90 dias após o transplante, $135,55 \mathrm{~cm}^{2}$, diferindo significativamente dos demais tratamentos, 120,42 e $102,93 \mathrm{~cm}^{2}$ para enxertias realizadas aos 60 e 30 dias após o transplante, respectivamente. Em relação ao comprimento total de raízes por muda, as maiores médias foram observadas para os tratamentos com enxertia aos 90 e 60 dias após o transplante, 288,08 e $275,90 \mathrm{~cm}$, respectivamente, os quais diferiram significativamente da época mais precoce de enxertia, $218,37 \mathrm{~cm}$. Estas diferenças são semelhantes às obtidas em relação aos pesos da matéria seca e fresca das raízes por muda, o que confirma a eficiência desta metodologia para a determinação da área e do comprimento total de raízes por muda através de imagem, podendo tornar-se uma excelente ferramenta em ensaios de propagação de plantas frutíferas sem que haja a necessidade da destruição das mesmas.

Neste trabalho, foram obtidos resultados promissores quanto à produção de mudas da videira 'Itália' por enxertia verde sobre os porta- 
enxertos IAC 766 'Campinas' e IAC 572 'Jales’ propagados por estaquia herbácea em câmara de nebulização, com altos índices médios de pegamento de enxertia quando esta foi realizada 90 dias após o tranplante dos porta-enxertos. Assim, o tempo necessário para a obtenção de uma muda de qualidade por este processo não deverá ser superior a 6-7 meses, considerando todas as etapas de propagação envolvidas.

Tendo em vista que no Brasil tem-se observado recentemente, na região Sul, a importação de mudas enxertadas para a formação de novos vinhedos (Regina, 2002), utilizando-se deste processo de propagação, é possível a produção de mudas de videiras e a um baixo custo operacional, o que poderá reduzir o tempo necessário para a formação de vinhedos comerciais. Além disso, este processo poderá permitir a economia de somas consideráveis de diversos gastos com a importação de mudas, além de evitar o risco de importação de pragas ainda inexistentes no País.

Por fim, nas diversas regiões produtoras de uvas no Brasil, existe atualmente uma preocupação bastante acentuada com relação aos porta-enxertos para a videira, principalmente quanto à diversificação em relação ao emprego de materiais que apresentem características adequadas para cada região. Neste trabalho, embora se tenha estudado a produção de mudas da videira 'Itália' enxertadas somente sobre os porta-enxertos IAC 766 'Campinas' e IAC 572 'Jales', espera-se que a metodologia empregada possa ser facilmente adaptada para outros portaenxertos empregados na viticultura nacional.

\section{CONCLUSÕES}

É possível a obtenção de mudas de videira 'Itália' em escala comercial realizando-se a enxertia verde 90 dias após o enraizamento dos porta-enxertos IAC 766 'Campinas' e IAC 572 'Jales' em câmara de nebulização.

\section{AGRADECIMENTOS}

Os autores expressam seus agradecimentos ao CNPq (Conselho Nacional de Desenvolvimento Científico e Tecnológico), pelo auxílio financeiro concedido para a realização do trabalho.

\section{REFERÊNCIASBIBLIOGRÁFICAS}

BIASI, L.A.; POMMER, C.V.; PINO, P.A.G.S. Propagação de portaenxertos de videira mediante estaquia semilenhosa. Bragantia, Campinas, v.56, n.2, p.367-376, 1997.

HARTMANN, H.T.; KESTER, D.E. Propagación de plantas, princípios y practicas. México: Continental, 1990.760p.

JORGE, L.A.C.; RALISCH, R.; ABI SAAB, O.J.G.; MEDINA, C.C.; GUIMARÃES, M.F.; NEVES, C.S.V.J.; CRESTANA, S.; CINTRA, F.L.D.; BASOI, L.H.; FERNANDES, S.B.V. Aquisição de imagens de raízes. In: JORGE, L.A.C. (Ed.) Recomendações práticas para aquisição de imagens digitais analisadas através do SIARCS $®$. São Carlos: EMBRAPA-CNPDIA, 1997. p.2-48 (Circular Técnica, 1).

NACHTIGAL, J.C. Obtenção de porta-enxertos 'Okinawa' e de mudas de pessegueiro (Prunus persica [L.] Batsch) utilizando métodos de propagação vegetativa. 1999. 165f. Tese (Doutorado em Produção Vegetal) - Faculdade de Ciências Agrárias e Veterinárias, Universidade Estadual Paulista, Jaboticabal, 1999.

PIRES, E.J.P.; BIASI, L.A. Propagação da videira. In: POMMER, C.V. (Ed.) Uva: tecnologia da produção, pós-colheita e mercado. Porto Alegre: Cinco Continentes, 2003. p.295-350.

REGINA, M.A. Produção de mudas de videira pela enxertia de mesa. Informe agropecuário, Belo Horizonte, v.23, n.216, p.25-35, 2002.

REZENDE, L.P.; PEREIRA, F.M. Produção de mudas de videira 'Rubi' pelo método de enxertia de mesa em estacas herbáceas dos portaenxertos IAC 313 'Tropical' e IAC 766 'Campinas'. Revista Brasileira de Fruticultura, Jaboticabal, v.23, n.3, p.662-667, 2001.

RÖBER, R. Substratos hortícolas: possibilidades e limites de sua composição e uso. Exemplos da pesquisa, da indústria e do consumo. In: KÄMPF, A.N.; FERMINO, M.H. (Ed.) Substrato para plantas: a base da produção vegetal em recipientes. Porto Alegre: Genesis, 2000. p.123-138.

SOUSA, J.S.I. Uvas para o Brasil. Piracicaba: FEALQ, 1996. 791p.

TERRA, M.M.; PIRES, E.J.P.; NOGUEIRA, N.A.M. Tecnologia para a produção de uva Itália na região noroeste do Estado de São Paulo. 2. ed. Campinas: Coordenadoria de Assistência Técnica Integral, 1998. 81p. (Documento Técnico, 97). 